\title{
Optimization of Environmentally Friendly Anodic Oxide Film for Magnesium Alloys
}

\author{
Masaaki Hara ${ }^{1}$, Kenji Matsuda ${ }^{1}$, Wataru Yamauchi ${ }^{1}$, Masaaki Sakaguchi ${ }^{2}$, \\ Toshiyuki Yoshikata ${ }^{2}$, Yorinobu Takigawa ${ }^{3}$ and Kenji Higashi ${ }^{3}$ \\ ${ }^{1}$ Shimano Co., Ltd., Sakai 590-8577, Japan \\ ${ }^{2}$ Okuno Chemical Industries Co., Ltd., Osaka 538-0044, Japan \\ ${ }^{3}$ Department of Materials Science, Faculty of Engineering, Osaka Prefecture University, Sakai 599-8531, Japan
}

\begin{abstract}
The magnesium anodizing treatment described in this paper is an environmentally friendly treatment which excludes the use of chromates, fluorine compounds, and phosphates. An alkali bath, which mimics conditions necessary to form naturally occurring magnesium salts, was selected as an electrolytic bath. The components of the electrolytic bath were optimized, and the samples were evaluated by salt spray test. The results suggest that the anodizing treatment with the optimized conditions on the surface of magnesium alloys AZ91 can achieve a higher level of corrosion resistance than the traditional chemical conversion and anodizing treatments which use chromates, fluorine compounds, and phosphates.
\end{abstract}

(Received November 21, 2005; Accepted March 13, 2006; Published April 15, 2006)

Keywords: magnesium alloys, anodizing, chemical conversion, corrosion resistance, chromates, fluorine compounds, phosphates, salt spray test

\section{Introduction}

Magnesium and magnesium alloys are some of the lightest of all the commercial metals, and have tensile strength higher than aluminum, copper, etc. ${ }^{1)}$ Utilizing these properties, applications to a variety of areas in which light weight is the concern have been sought. ${ }^{2,3)}$

On the other hand, there are many problems associated with corrosion, because magnesium is one of the base metals used commercially and is electrochemically highly active. To overcome these problems, many studies have been carried out in the area of material science, enabling the supply of materials with superior quality. ${ }^{4)}$ Numerous research has been carried out on the surface treatment methods as well. ${ }^{5-7)}$ The surface treatment methods to improve the corrosion resistance of magnesium alloys are described in JIS H 8651.

A magnesium surface naturally develops a base, magnesium hydroxide film, $\operatorname{Mg}(\mathrm{OH})_{2}$. Because this film does not necessarily protect the substrate magnesium under all types of environments, some type of surface treatment is necessary. The surface treatments for magnesium are roughly categorized into two types: chemical conversion and anodizing. The chemical conversion treatment is a method in which a corrosion resistant film is chemically formed on the surface of magnesium, principally by immersion. Because this method is inexpensive, the majority of indoor electric appliances made of magnesium are surface treated by chemical conversion followed by coating. 8 ,9) The latter method, anodizing treatment, is a method in which the magnesium is immersed in the treatment liquid and the film is electrochemically formed on the surface. For products such as high quality outdoor sport products, in which light weight and compact size are desired, corrosion resistance and wear resistance are required. Anodizing treatment is essential ${ }^{10,11)}$ under such harsh corrosive environments. In the traditional anodizing methods, solutions such as chromates, fluorine compounds, and phosphates are used. ${ }^{1)}$ However, it has been suggested that these components have a high environmental load ${ }^{11)}$ therefore, development of anodizing treatment methods using a more environmentally sound solution is demanded.

In this study, highly corrosion resistant anodizing coatings that use environmentally friendly electrolytes, which contain film components free of chromates, fluorine compounds, and phosphates, but contain silicates, carbonates, etc., and can be performed in a sound work environment were examined, mimicking the oxidized film components occurring in nature. ${ }^{12)}$

\section{Methods of Experiment}

\subsection{Dimension and shape of the specimens}

As shown in Table 1, magnesium alloy die cast AZ91D was used in the study. The alloy was die cast in a hot chamber machine with the mold temperature at $200^{\circ} \mathrm{C}$, injection speed at $2.6 \mathrm{~m} / \mathrm{s}$, into $W: 70 \mathrm{~mm} \times L: 150 \mathrm{~mm} \times t: 3 \mathrm{~mm}$, and then cut into $W: 70 \mathrm{~mm} \times L: 50 \mathrm{~mm} \times t: 3 \mathrm{~mm}$. The surface roughness of one side of the specimens was adjusted to approximately $R a=1$ with emery paper \#320.

\subsection{Anodizing}

The specimens prepared by the method described in Section 2.1 were degreased with a weak alkali and anodized under the conditions shown in Table 2. For comparison, a traditional method, DOW17 (250 g/L ammonium hydrogen fluoride, $100 \mathrm{~g} / \mathrm{L}$ sodium dichromate, and $90 \mathrm{~mL} / \mathrm{L}$ phosphoric acid), was also used to prepare specimens.

The moderate degree of chemical dissolution and formation of insoluble anodic oxide film are the important factors for the formation of anodic oxide film on magnesium alloys

Table 1 Chemical composition of AZ91D.

\begin{tabular}{ccccccccc}
\hline mass\% & $\mathrm{Al}$ & $\mathrm{Zn}$ & $\mathrm{Si}$ & $\mathrm{Mn}$ & $\mathrm{Fe}$ & $\mathrm{Cu}$ & $\mathrm{Ni}$ & $\mathrm{Mg}$ \\
\hline AZ91D & 9.12 & 0.67 & 0.02 & 0.24 & 0.001 & 0.002 & 0.001 & bal.
\end{tabular}


when determining the type of electrolyte to be used for magnesium anodizing. In fact, it is reported that in the traditional anodizing method for magnesium alloy, DOW17, a considerable amount of fluorine, which is a component of electrolyte, is contained in the anodic oxide film in the form of magnesium compound. ${ }^{4)}$ Accordingly, in this study, it was intended to exclude environmentally harmful electrolyte components such as chromates, fluorine compounds, and phosphates, and instead, to select electrolytes containing naturally occurring oxide components, such as silicates and carbonates etc. However, electrolytes containing such components cannot develop a film due to the strong chemical dissolution occurring in acidic solutions. Therefore, it was decided to examine electrolyte components for the alkali bath because magnesium is stable in a strong alkaline solution. Ono and coworkers suggested that in the sodium hydroxide bath, which is an alkali bath, the film changed to barrier layer anodic oxide film, semi-barrier layer anodic oxide film, and porous anodic oxide film with change in the current due to the voltage difference and depending on varying conditions. ${ }^{2)}$ Based on these observations, together with the consideration of the voltage specific properties, electrolyte components were selected based on the following reasons:

Table 2 Bath composition and condition of anodizing.

\begin{tabular}{llrc}
\hline & \multicolumn{2}{c}{ Bath composition } & Condition \\
\hline \multirow{4}{*}{ anodizing } & $\mathrm{Na}_{2} \mathrm{O} \cdot \mathrm{SiO}_{2}$ & $50 \mathrm{~g} / \mathrm{L}$ & current density \\
& $\mathrm{KOH}$ & $50 \mathrm{~g} / \mathrm{L}$ & $3 \mathrm{~A} / \mathrm{dm}^{2}$ \\
& $\mathrm{Na}_{2} \mathrm{CO}_{3}$ & $0-80 \mathrm{~g} / \mathrm{L}$ & temperature $25^{\circ} \mathrm{C}$ \\
& $\mathrm{Na}_{2} \mathrm{~B}_{4} \mathrm{O}_{7}$ & $0-30 \mathrm{~g} / \mathrm{L}$ & time 0-30 min \\
\hline
\end{tabular}

1) It is considered that carbonates mainly prevent dissolution of magnesium in the electrolyte and promote the growth of magnesium oxide.

2) Borates work effectively to develop fine film.

3) Silicates deposit on the material surface to become a component of oxidic film as magnesium silicate.

After these issues were examined, it was decided to use potassium hydroxide as a base to add conductivity to the electrolyte, and sodium metasilicate, sodium carbonate, and sodium borate. In the anodizing treatment, aluminum wires were used for racking, and carbon plates were used as electrodes.

\subsection{Chemical conversion}

Chemical conversion treatment, MX3, which is described in JIS-H8651 as a suitable method for corrosion protection and coating base, was also performed for comparison with

Table 3 Bath composition and condition of chemical conversion.

\begin{tabular}{lccc}
\hline (MX3) & \multicolumn{3}{c}{ Composition and condition } \\
\hline \multirow{2}{*}{ first } & $\mathrm{NH}_{4} \mathrm{HF}_{2}$ & $50 \mathrm{~g} / \mathrm{L}$ & $20^{\circ} \mathrm{C} \times 5 \mathrm{~min}$ \\
\hline \multirow{2}{*}{ second } & $\mathrm{Na}_{2} \mathrm{Cr}_{2} \mathrm{O}_{7}$ & $120 \mathrm{~g} / \mathrm{L}$ & $95^{\circ} \mathrm{C} \times 30 \mathrm{~min}$ \\
& $\mathrm{Ca}\left(\mathrm{HF}_{2}\right)_{2}$ & $2.5 \mathrm{~g} / \mathrm{L}$ & \\
\hline
\end{tabular}

Table 4 Effect of $\mathrm{Na}_{2} \mathrm{O} \cdot \mathrm{SiO}_{2} / \mathrm{KOH}$ ratio on formation of anodic oxide film in $\mathrm{Mg}$ anodizing bath.

\begin{tabular}{|c|c|c|c|c|}
\hline & $\mathrm{KOH}(50 \mathrm{~g} / \mathrm{L})$ & $3 \mathrm{~A} / \mathrm{dm}^{2}$ & $30 \mathrm{~min}$ & $25^{\circ} \mathrm{C}$ \\
\hline$(\mathrm{g} / \mathrm{L})$ & 20 & 50 & 80 & 120 \\
\hline $\mathrm{Na}_{2} \mathrm{O} \cdot \mathrm{SiO}_{2}$ & no formation & discharge & partia & 1 formation \\
\hline
\end{tabular}

Table 5 Effect of $\mathrm{Na}_{2} \mathrm{CO}_{3} / \mathrm{Na}_{2} \mathrm{~B}_{4} \mathrm{O}_{7}$ ratio on formation of anodic oxide film in $\mathrm{Mg}$ anodizing bath.

\begin{tabular}{|c|c|c|c|c|c|}
\hline $\mathrm{KOH}(50 \mathrm{~g} / \mathrm{L})$ & & \multicolumn{4}{|c|}{$3 \mathrm{~A} / \mathrm{dm}^{2}, 30 \mathrm{~min}, 25^{\circ} \mathrm{C}$} \\
\hline \multirow{2}{*}{$\begin{array}{c}\mathrm{Na}_{2} \mathrm{O} \cdot \mathrm{SiO}_{2} \\
(50 \mathrm{~g} / \mathrm{L})\end{array}$} & \multirow{2}{*}{ 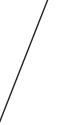 } & \multicolumn{4}{|c|}{$\mathrm{Na}_{2} \mathrm{CO}_{3}(\mathrm{~g} / \mathrm{L})$} \\
\hline & & 0 & 20 & 50 & 80 \\
\hline \multirow{8}{*}{$\mathrm{Na}_{2} \mathrm{~B}_{4} \mathrm{O}_{7}(\mathrm{~g} / \mathrm{L})$} & \multirow{2}{*}{0} & $101 \mathrm{~V}$ & & & $72 \mathrm{~V}$ \\
\hline & & pit of discharge & & & $\mathrm{Ra}=2.8$ \\
\hline & & & $97 \mathrm{~V}$ & $84 \mathrm{~V}$ & \\
\hline & 10 & & partial & $\mathrm{Ra}=2.7$ & \\
\hline & & & $97 \mathrm{~V}$ & $84 \mathrm{~V}$ & \\
\hline & 20 & & partial & $\mathrm{Ra}=3.3$ & \\
\hline & & $99 \mathrm{~V}$ & & & $74 \mathrm{~V}$ \\
\hline & & pit of discharge & & & $\mathrm{Ra}=3.5$ \\
\hline
\end{tabular}


the anodizing method. The bath composition and treatment conditions are listed in Table 3.

\subsection{Measurement of surface roughness}

To determine how the surface roughness of the anodized specimens varies by different treatment conditions, Ra was measured by a surface roughness measurement tester.

\subsection{The SEM and FE-SEM analysis of the top surface}

The anodized top surface was observed by scanning electron microscopy to examine how the morphology differs by different treatment conditions. The coating elements were analyzed by EDS. The top surface was observed by FE-SEM at high magnification $\left(1 \times 10^{5}\right)$.

\subsection{Identification of film components by X-ray diffrac- tion}

X-ray diffraction was carried out to determine the compounds composed of the film that was formed on the anodized surface of the specimens.

\subsection{Corrosion resistance evaluation of the conversion film and anodic oxide film}

A salt spray test, which is defined in JIS Z2371, was performed to test the corrosion resistance. Evaluation was carried out by comparing the appearance and the weight decrease as a result of corrosion by a cycle of $24 \mathrm{~h}$. After $192 \mathrm{~h}$ (eight cycles), the specimens were immersed in $20 \mathrm{~g} / \mathrm{L}$ sodium bichromate at $25^{\circ} \mathrm{C}$ for five minutes to remove the corrosion product, followed by surface washing.

\section{Results and Examination}

\subsection{Electrolyte components of the anodizing treatment}

A preliminary experiment was carried out to determine the electrolyte components to be used in the experiment (Tables 4 and 5). To examine the electrolyte components, it was decided to start by adding various types of salts to $50 \mathrm{~g} / \mathrm{L}$ potassium hydroxide, which served as a conductive salt. As shown in Table 4, with the potassium hydroxide being kept constant at $50 \mathrm{~g} / \mathrm{L}$, when sodium silicate was low, film was not formed; when it was excess, anomalous white powder growth was partially observed. Accordingly, it was decided to adjust the amount of sodium carbonate and sodium borate added while the amount of sodium silicate is fixed at $50 \mathrm{~g} / \mathrm{L}$. In Table 5, the final forming voltages are shown in the upper row, and the surface roughness $R a$ values are in the bottom row. While keeping potassium hydroxide and sodium silicate constant at $50 \mathrm{~g} / \mathrm{L}$, current density at $3 \mathrm{~A} / \mathrm{dm}^{2}$, and treatment time for $30 \mathrm{~min}$, the difference by varying the amount of sodium carbonate and sodium borate was analyzed. As shown in Table 5, the final forming voltage decreased with the addition of sodium carbonate. When no sodium carbonate was added, numerous pits, presumably electric discharge marks, were observed. And the appearance of anomalous growth of film was partially observed with the addition of $20 \mathrm{~g} / \mathrm{L}$ of sodium carbonate. When the amount of added sodium carbonate reached $50 \mathrm{~g} / \mathrm{L}$ or more, there was no difference in terms of the appearance of the specimens. Although the addition of sodium borate did not lower the final forming voltage, the spark discharge during anodizing tended to be concentrated to one locus, and the forming voltage swung greatly. When $20 \mathrm{~g} / \mathrm{L}$ of sodium borate is added, spark discharge occurred all over the specimens with the forming voltage being relatively constant. Accordingly, the following examination was carried out based on this conditions $(50 \mathrm{~g} / \mathrm{L}$ potassium hydroxide, $50 \mathrm{~g} / \mathrm{L}$ sodium silicate, $50 \mathrm{~g} / \mathrm{L}$ sodium carbonate, $20 \mathrm{~g} / \mathrm{L}$ sodium borate) of as the optimized conditions.

\subsection{The surface roughness of the anodizing specimen and the conversion treated specimen}

Anodizing was carried out based on the conditions determined in Section 3.1, and the surface roughness $R a$ and the anodic oxide film thickness were measured. The results are shown in Fig. 1. As can be seen in Fig. 1, in the early film formation phase, the surface prepared with the \#320 emery paper once became smooth due to the dissolution by anodizing treatment, then the roughness $R a$ increased with an increase in the treatment time. The film thickness increased as the treatment time increased. On the other hand, surface roughness $(R a=1.2)$ of the specimens prepared by the conversion treatment did not differ at a detectable level,
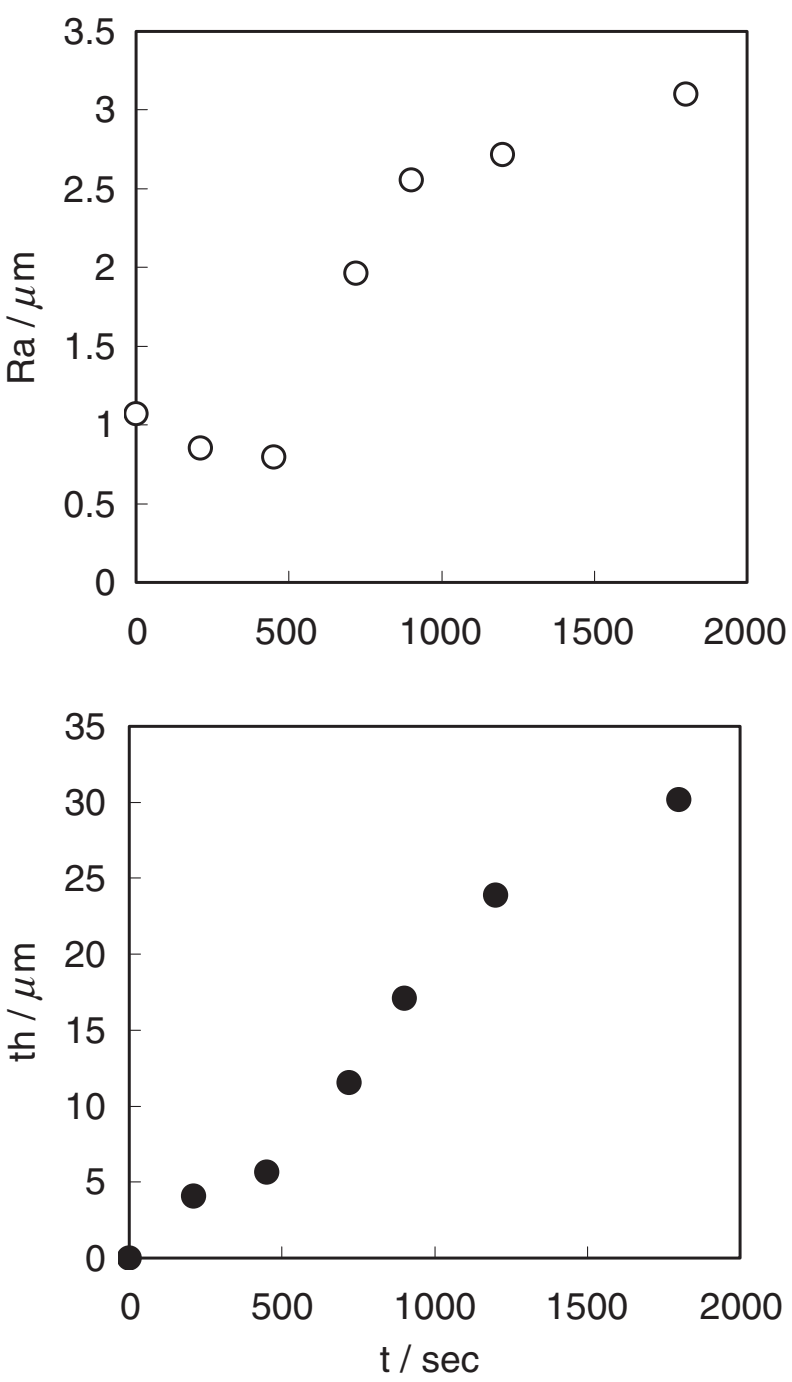

Fig. 1 Change in surface roughness and thickness by anodizing time in the specimens anodized in the optimized condition. 


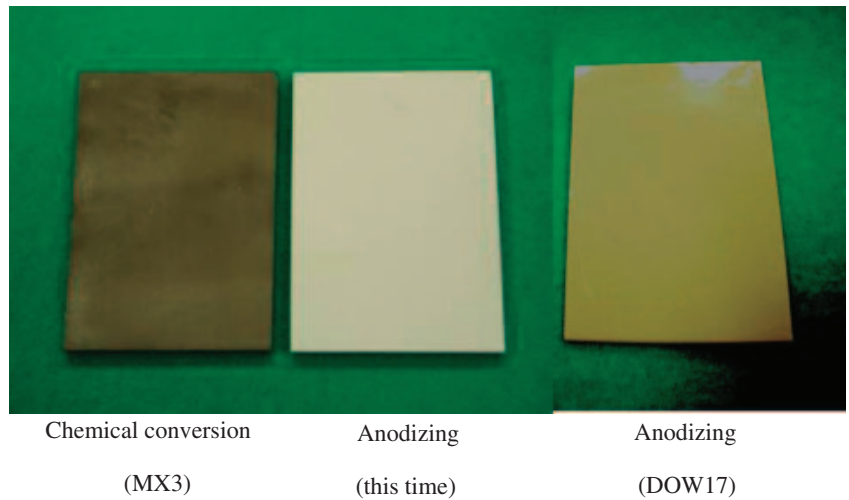

Fig. 2 Appearance of anodizing and chemical conversion.

being roughly the same as the surface prepared with the \#320 emery paper. Figure 2 shows the appearance of these specimens. A rough, white layer was formed on the anodized specimen; a brown chromate film was formed on the conversion treated specimen. A green film was formed on the specimen treated by the DOW17 method for ten minutes, with the surface roughness $R a$ being 3.2.

\subsection{Analysis of the top surface of the anodic oxide film of magnesium by SEM and FE-SEM, XRD, and EDS}

The photographic images of the top surface of the post magnesium anodizing treatment are shown in Fig. 3. As can be seen in Fig. 3, the surface has considerably rugged topography. Ono and colleagues suggest that the structure of the anodic oxide film formed on die cast materials largely depends on the surface structure of the material die cast. ${ }^{4)}$
The factors include intermetallic compounds of grain boundary, large and small voids, and cavities. Such materials are accompanied by spark discharge and gas generation, due to the dielectric breakdown at the time of film formation. ${ }^{4)}$ Consequently, the surface is highly rugged, and in some areas there are crack-like features. Such conditions are similar to those seen on the specimen prepared by the DOW17 method.

The top surface was also observed by FE-SEM. As shown in the images in Fig. 4, locus 1 exhibits microporous structure, locus 2 globular structure, and locus 3 coexistence of microporous and globular structures. These observations are in agreement with those for DOW17. ${ }^{13)}$ A clear, ordered microporous structure, which is observed in the anodic oxide film of aluminum, was not observed in this study.

Since the analysis of the top surfaces by SEM suggested a formation of crystalline substances, X-ray diffraction was carried out to identify the compounds. The diffraction pattern shows the peaks of the substrate magnesium and the peaks of $\mathrm{Mg}_{2} \mathrm{SiO}_{4}$, indicating that the anodic oxide film formed in this bath is composed of $\mathrm{Mg}_{2} \mathrm{SiO}_{4}$ (Fig. 5).

Further, the elements consisting of the anodic oxide film were analyzed by EDS. The results are shown in Fig. 6. As can be seen in Fig. 6, Mg, $\mathrm{Si}, \mathrm{Na}, \mathrm{K}, \mathrm{O}$, and $\mathrm{Al}$ were detected in descending order; but $\mathrm{Zn}$, which is contained in the substrate alloy, was not detected, indicating that $\mathrm{Zn}$ is absent in the anodic oxide film and was probably dissolved into the electrolyte. It is supposed that $\mathrm{Si}, \mathrm{Na}, \mathrm{K}$ and $\mathrm{O}$ are the salts formed from sodium metasilicate $\left(\mathrm{Na}_{2} \mathrm{O} \cdot \mathrm{SiO}_{2}\right)$, sodium borate $\left(\mathrm{Na}_{2} \mathrm{~B}_{4} \mathrm{O}_{7}\right)$, sodium carbonate $\left(\mathrm{Na}_{2} \mathrm{CO}_{3}\right)$, and potassium hydroxide $(\mathrm{KOH})$, all of which are the bath components.
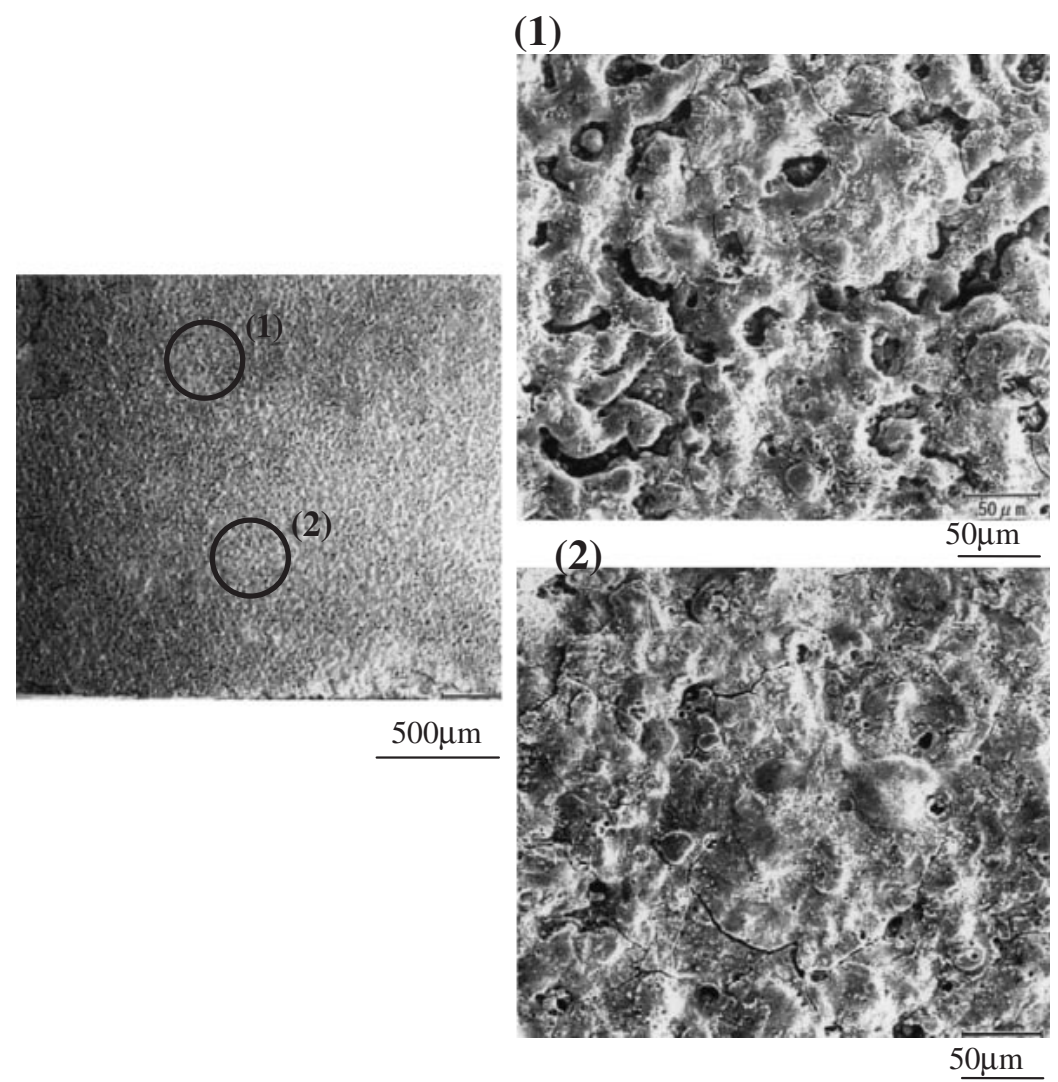

Fig. 3 SEM images of Mg anodizing layer in the specimens anodized in the optimized condition. 


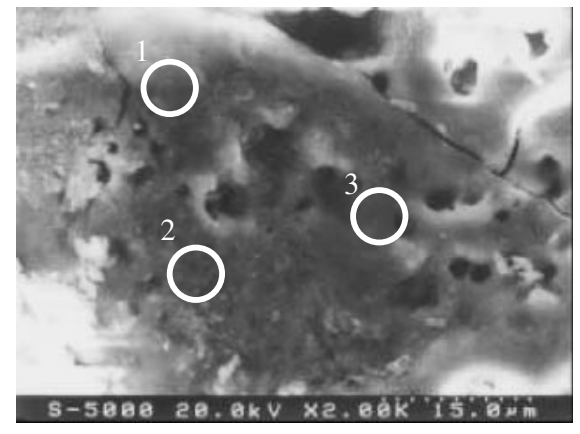

$15 \mu \mathrm{m}$
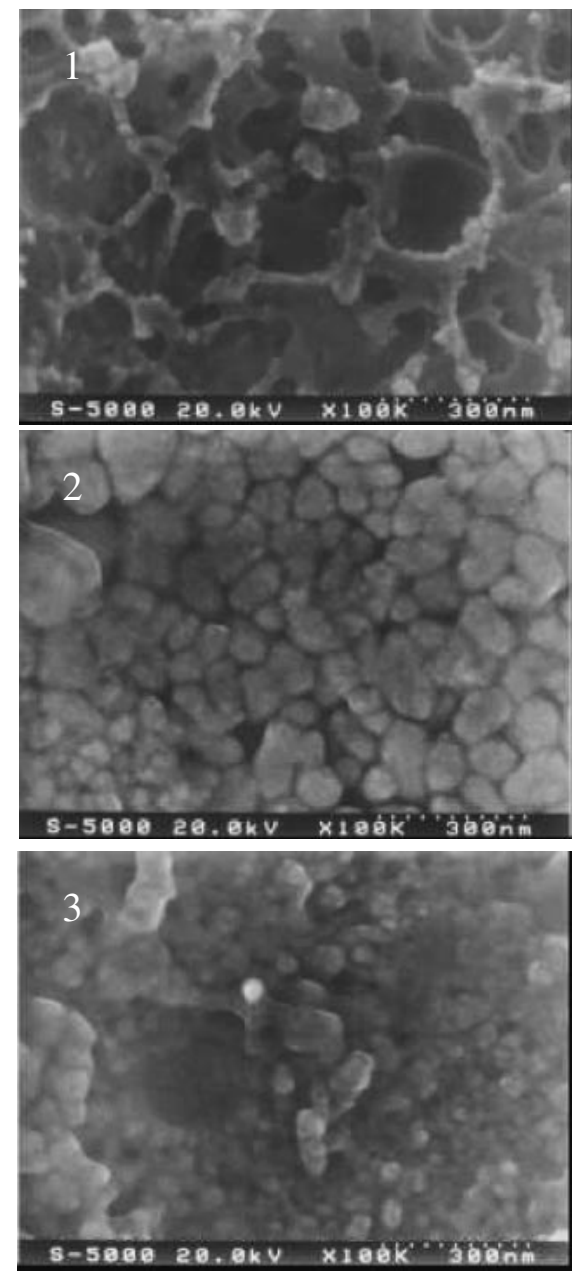

$300 \mathrm{~nm}$

Fig. 4 Top surface picture of anodizing by FE-SEM in the specimens anodized in the optimized condition.

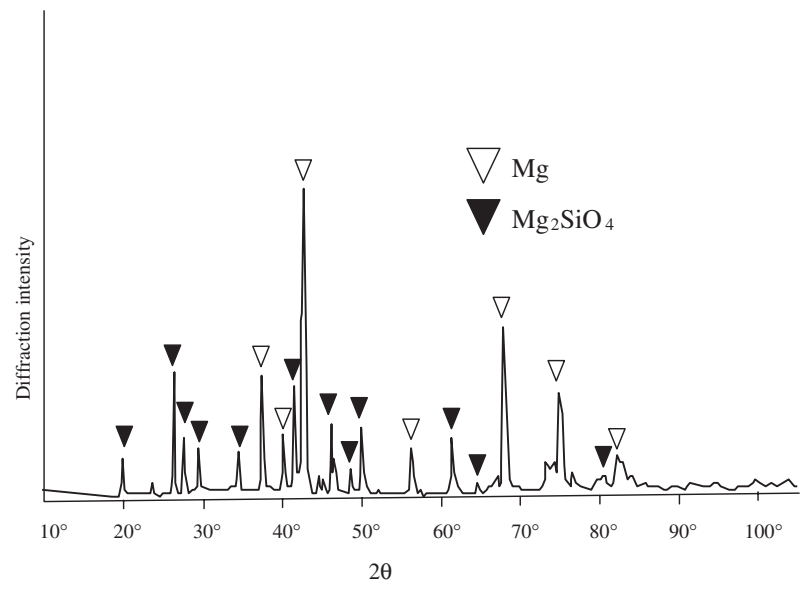

Fig. 5 Peak of X-ray diffraction pattern in the specimens anodized in the optimized condition.

\subsection{Comparison of corrosion resistance between the specimen with chemical conversion, traditional anodized and anodized specimens by salt spray test}

Corrosion resistance of the sample with chemical conversion coating, DOW17 sample, and anodized specimen for this study were compared by a cycle of $24 \mathrm{~h}$. Figure 7 shows the appearance of the samples after the testing. Corrosion pits

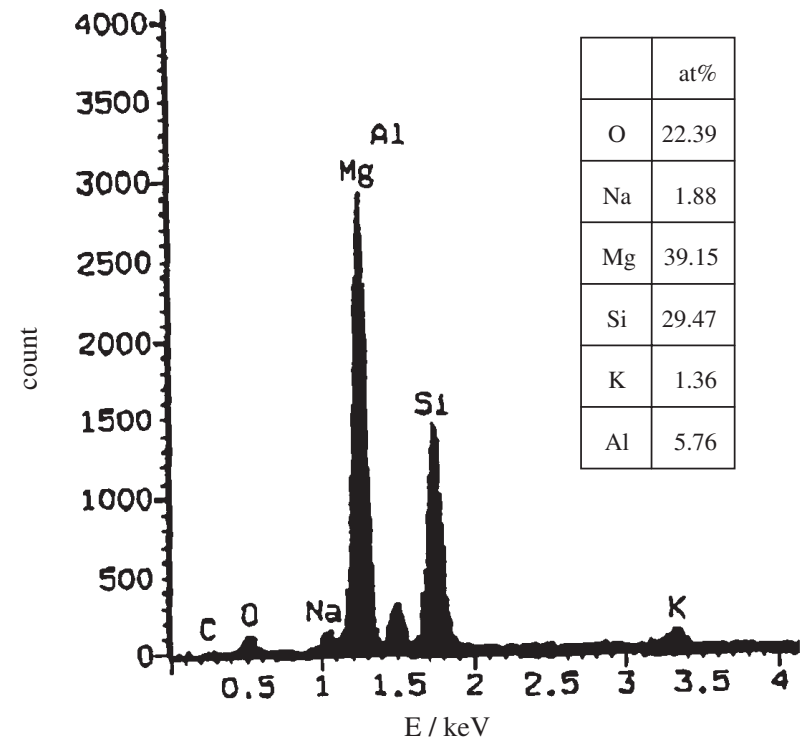

Fig. 6 EDS analysis of anodizing layer in the specimens anodized in the optimized condition.

were found by the naked eye on the specimen with conversion coating $24 \mathrm{~h}$ after the salt spray test. Also noted is that as shown in Fig. 7, the originally uniform, brown 


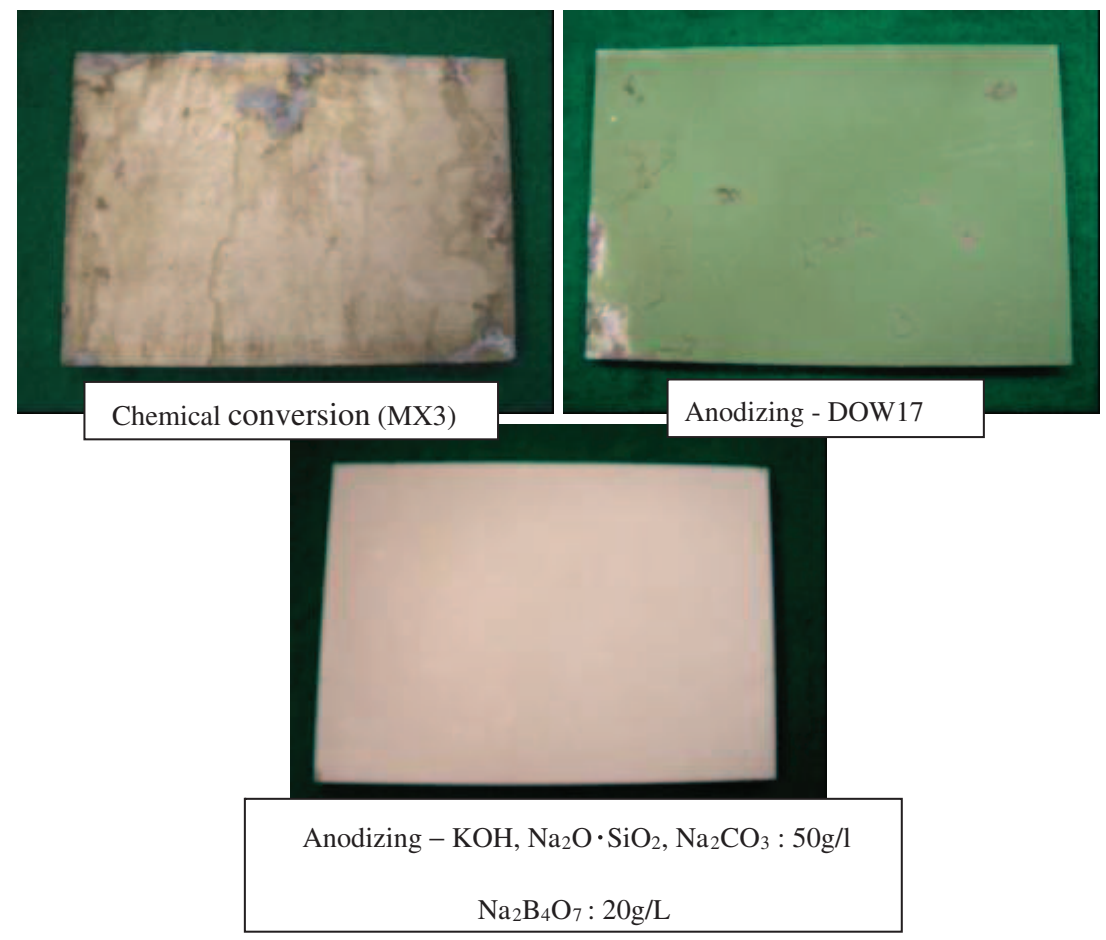

Fig. 7 Appearance of the specimens after salt spray test for $192 \mathrm{~h}$.

chromate film on this specimen is discolored by corrosion, which progressed with time. The DOW17 sample has corrosion marks which are clearly observed by the naked eye, $192 \mathrm{~h}$ after the test. On the anodized specimen for this study, on the other hand, no corrosion marks which could be detected by the naked eye were observed even $192 \mathrm{~h}$ after the test. The film thickness of the DOW17 sample is approximately $30 \mu \mathrm{m}$, the film is considerably rugged, has thick and thin areas, and voids are likely present within the film, as suggested by Ono and others. ${ }^{13)}$ The anodic oxide film on the specimen for this study also is rugged, and the film thickness is roughly $30 \mu \mathrm{m}$. Therefore, it is clear from the difference in the appearances that the anodic oxide film on the sample prepared by the method for this study is superior to that prepared by the DOW17 method. It is suspected that the difference in the corrosion resistance between DOW17 and the anodized specimen for this study resulted from the difference in the electrical conductivity between the anodic oxide film components of these specimens: $\mathrm{Cr}_{2} \mathrm{O}_{3}, \mathrm{MgF}_{2}$ and $\mathrm{NaMgF}_{3}$ for the DOW17 specimens and $\mathrm{Mg}_{2} \mathrm{SiO}_{4}$ for the anodized specimen for this study. The former is considered to have higher electrical conductivity than the latter, which resulted in the greater degree of galvanic corrosion of substrate (anode) compared with the anodic oxide film (cathode). Further study is necessary to understand the detailed mechanism.

To quantify the degree of corrosion by salt spray test, the weight reduced by corrosion was examined. The specimens would gain weight after the salt spray test due to the corrosion products, such as hydroxides, which add to the weight. Accordingly, the corrosion product was removed by $20 \mathrm{~g} / \mathrm{L}$ of sodium bichromate solution at $25^{\circ} \mathrm{C}$ for $5 \mathrm{~min}$, which selectively removes the corrosion product while protecting the metal surface from dissolution by the effect

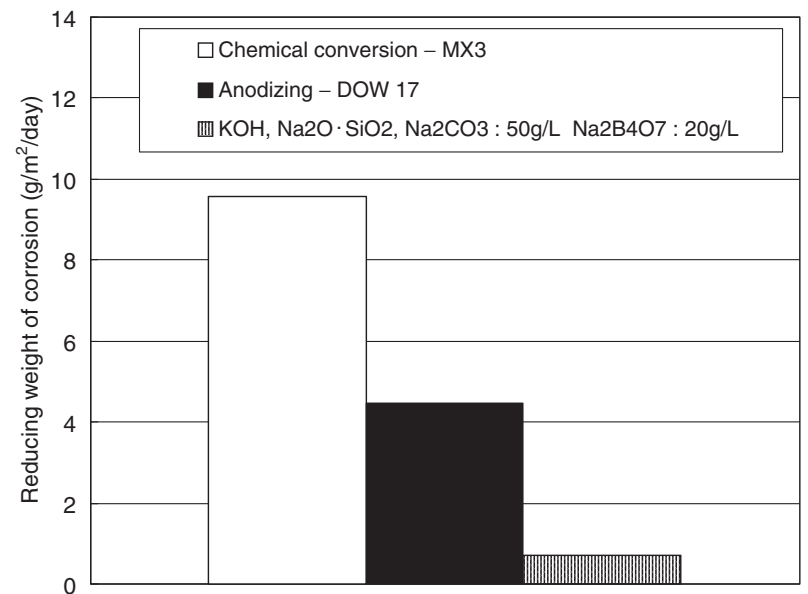

Fig. 8 Weight of corrosion by salt spray test for $192 \mathrm{~h}$.

of chromate; the reduced weight by this method was defined as corrosion reduction $\left(\mathrm{g} / \mathrm{m}^{2} /\right.$ day $)$. There was no weight change on anodized film by dissolution at dipping. The results are shown in Fig. 8. As can be seen in Fig. 8, the amount of corrosion reduction for the anodized specimen prepared by the method for this study was clearly lower than the chemical conversion and DOW17 specimens, with the improvement of corrosion resistance being about ten times the chemical conversion specimen, and five times the DOW17 specimen. As we have seen, it is clear that the anodic oxide film for this study, which is free of chromates, fluorine compounds, and phosphates, is a more effective environmentally friendly and corrosion resistant surface finish than the chemical conversion film or traditional anodic oxide film which use such substances. 


\section{Summary}

In order to establish a treatment method for a highly corrosion resistant surface for magnesium, an environmentally friendly anodizing method which is free of chromates, fluorine compounds, and phosphates was examined by comparing with the preexisting chemical conversion method for magnesium.

(1) Considering the appearance basis corrosion resistance and surface roughness after the anodizing process depending on the homogeneity of spark discharge and stability of voltage variance, the optimum condition for the electrolytic bath components for this study was determined as $50 \mathrm{~g} / \mathrm{L}$ each of potassium hydroxide, sodium metasilicate, and sodium carbonate, and $20 \mathrm{~g} / \mathrm{L}$ of sodium borate.

(2) The SEM analysis shows that the top surface morphology of the anodic oxide film for this study is similar to that of DOW17, exhibiting rugged topography. The film thickness and surface roughness $R a$ increased with time. In the FE-SEM analysis, there is no clear microporous structure, which is typically seen on the aluminum anodic oxide film, found on the anodic oxide film prepared by the method for this study.

(3) The X-ray diffraction analysis indicates that the main component of the film is $\mathrm{Mg}_{2} \mathrm{SiO}_{4}$, and $\mathrm{Mg}, \mathrm{Si}, \mathrm{Na}, \mathrm{K}$, $\mathrm{O}$, and $\mathrm{Al}$ were detected by the EDS analysis. Therefore, it is suspected that the anodic oxide film in the study principally consists of $\mathrm{Mg}_{2} \mathrm{SiO}_{4}$ and that $\mathrm{Na}, \mathrm{K}$, and $\mathrm{Al}$ exist in certain forms. However, the forms of the compound could not be obtained in this study.

(4) The corrosion resistance of the specimen for the study was evaluated by the observation $192 \mathrm{~h}$ after the salt spray test. The results show that on the basis of reduced weight by corrosion, the anodic oxide film for this study is approximately ten times superior to the film prepared by the traditional chemical conversion MX3, and approximately five times superior to the anodized film prepared by the traditional DOW17 method.

(5) The anodizing bath for magnesium used in this study is free of chromates, fluorine compounds, and phosphates, and can provide corrosion resistance which is superior to the traditional chemical conversion and anodizing treatments that contain these substances.

\section{REFERENCES}

1) F. Sato, Y. Asakawa, T. Nakayama and H. Sato: J. JILM 42 (1992) 753-758.

2) S. Ono: Journal of The Japanese Anodizing Association 5 (2002) 4249.

3) M. Hino and M. Hiramatsu: Plating Technology 4 (2004) 1-8.

4) S. Ono: Journal of The Surface Finishing Society of Japan 53 (2002) 166-171.

5) S. Ono and N. Masuko: Journal of The Surface Finishing Society of Japan 44 (1993) 927-929.

6) Ross Phillip N., Jhon A. Macculloch, Graham A. Wright, Ellen A. Carter and Thomas F. Barton: SAE TECHNICAL PAPER SERIES, 980088 (1998) 1-4.

7) J. E. Gray and B. Luan: Journal of Alloys and Compounds 336 (2002) 88-113.

8) S. Ono, M. Saito, M. Horiguchi, K. Terashima, K. Matsuzaka, A. Shida, T. Osaka and N. Masuko: Journal of The Surface Finishing Society of Japan 47 (1996) 263-267.

9) S. Ono, K. Asami and N. Masuko: Materials Transactions 42 (2001) 1225-1231.

10) F. Sato and Y. Asakawa: J. JILM 44 (1994) 104-109.

11) F. Sato, Y. Asakawa, T. Nakayama and H. Sato: J. JILM 43 (1993) 6570 .

12) Unexamined patent application publication number: 2004-91911.

13) S. Ono, M. Saito, M. Horiguchi, K. Terashima, K. Matsuzaka, A. Shida and T. Osaka: Journal of The Surface Finishing Society of Japan, 47 (1996) 268-272. 